\title{
Validity of urinary monoamine assay sales under the "spot baseline urinary neurotransmitter testing marketing model"
}

This article was published in the following Dove Press journal: International Journal of Nephrology and Renovascular Disease 19 July 2011

Number of times this article has been viewed

\section{Marty Hinz'}

Alvin Stein ${ }^{2}$

Thomas Uncini ${ }^{3}$

'Clinical Research, Neuro Research Clinics Inc, Cape Coral, FL; ${ }^{2}$ Stein Orthopedic Associates, Plantation, FL; ${ }^{3}$ Laboratory, Fairview Regional Medical Center-Mesabi, Hibbing, MN, USA
Correspondence: Marty Hinz 1008 Dolphin Dr, Cape Coral, FL 33904, USA

$\mathrm{Tel}+\mathrm{I} 2186262220$

Fax +I 2186261638

Email marty@hinzmd.com

\begin{abstract}
Spot baseline urinary monoamine assays have been used in medicine for over 50 years as a screening test for monoamine-secreting tumors, such as pheochromocytoma and carcinoid syndrome. In these disease states, when the result of a spot baseline monoamine assay is above the specific value set by the laboratory, it is an indication to obtain a 24-hour urine sample to make a definitive diagnosis. There are no defined applications where spot baseline urinary monoamine assays can be used to diagnose disease or other states directly. No peer-reviewed published original research exists which demonstrates that these assays are valid in the treatment of individual patients in the clinical setting. Since 2001, urinary monoamine assay sales have been promoted for numerous applications under the "spot baseline urinary neurotransmitter testing marketing model". There is no published peer-reviewed original research that defines the scientific foundation upon which the claims for these assays are made. On the contrary, several articles have been published that discredit various aspects of the model. To fill the void, this manuscript is a comprehensive review of the scientific foundation and claims put forth by laboratories selling urinary monoamine assays under the spot baseline urinary neurotransmitter testing marketing model.
\end{abstract}

Keywords: monoamine, serotonin, dopamine, norepinephrine, epinephrine, urine, urinary

\section{Introduction}

About 10 years ago, a laboratory began selling urinary monoamine assays under the "spot baseline urinary neurotransmitter testing marketing model". It was claimed that these assays had a direct relationship with the levels of the monoamine neurotransmitters in the brain and peripheral nervous system. The marketing model also made numerous previously unknown claims regarding medical applications of urinary monoamine assays. Attached to each monoamine assay report from the laboratory were recommendations for treating monoamine neurotransmitter-related diseases, such as depression and attention deficit hyperactivity disorder, using nutritional supplements in conjunction with the testing. The recommended nutritional supplements in all cases were sold exclusively by those selling the laboratory assays. ${ }^{1-4}$ This medical treatment methodology continues to be marketed today by several laboratories, physicians, other types of caregivers, and directly to the public over the Internet. In the process, the scope of urinary monoamine assay marketing claims has increased. This review examines the validity of this approach.

Without the benefit of published peer-reviewed research discussing or supporting the scientific foundation of the testing, many physicians and caregivers have joined laboratories in expanding the Internet marketing campaign for this type of testing coupled with nutritional supplement sales. ${ }^{1-4}$ 
This manuscript reviews and discusses the validity of clinical applications promoted to enhance the sales of urinary serotonin, dopamine, norepinephrine, and/or epinephrine (herein referred to as "monoamine") assays. The reference point for this discussion and review is ten peer-reviewed research papers relating to clinical applications of monoamine assays published by the authors of this manuscript since 2009 (as listed in Table 1). ${ }^{5-14}$

The topic is the rationale, validity, and clinical impact of marketing claims used to sell urinary monoamine assays under the "spot baseline urinary neurotransmitter testing marketing model". It is the hypothesis of this manuscript that

Table I Overview and summary of previous papers by the authors of this paper

\begin{tabular}{|c|c|}
\hline Authors & Comments \\
\hline Hinz $z^{5}$ & $\begin{array}{l}\text { Use of serotonin and dopamine precursors guided } \\
\text { by organic cation transporter optimization in the } \\
\text { treatment of depression. }\end{array}$ \\
\hline Trachte et al ${ }^{14}$ & $\begin{array}{l}\text { This is written by the chairman of the research } \\
\text { committee, University of Minnesota Medical School, } \\
\text { Duluth, MN, based on laboratory data provided by and } \\
\text { in collaboration with Marty Hinz. The paper documents } \\
\text { the response of urinary serotonin and dopamine to } \\
\text { administration of L-tyrosine in a large group. }\end{array}$ \\
\hline Hinz et $\mathrm{al}^{6}$ & $\begin{array}{l}\text { Publishing of a new organic cation transporter model } \\
\text { relating to monoamine transport. }\end{array}$ \\
\hline Hinz et $\mathrm{al}^{7}$ & $\begin{array}{l}\text { Discusses the validity of day to day reproducibility of } \\
\text { spot baseline urinary serotonin and dopamine samples } \\
\text { in the same subject. Findings were that testing differs } \\
\text { significantly from day to day in the same subject and is } \\
\text { not reproducible. }\end{array}$ \\
\hline Hinz et $\mathrm{al}^{8}$ & $\begin{array}{l}\text { Differentiation of major affective disorder from } \\
\text { depression-dominant bipolar disorder and treatment } \\
\text { with serotonin and dopamine amino acid precursors, } \\
\text { guided by transporter assay optimization. }\end{array}$ \\
\hline Stein et $\mathrm{al}^{13}$ & $\begin{array}{l}\text { A treatment protocol for treatment of Crohn's disease } \\
\text { with amino acids guided by organic cation transporter } \\
\text { functional status determination. }\end{array}$ \\
\hline Hinz et al ${ }^{9}$ & $\begin{array}{l}\text { Treatment of attention deficit hyperactivity } \\
\text { disorder with serotonin and dopamine amino acid } \\
\text { precursors, guided by organic cation transporter assay } \\
\text { optimization. }\end{array}$ \\
\hline Hinz et $\mathrm{al}^{10}$ & $\begin{array}{l}\text { Discusses the validity of day to day reproducibility of } \\
\text { spot baseline urinary norepinephrine and epinephrine } \\
\text { samples in the same subject. Findings were that testing } \\
\text { differs significantly from day to day in the same subject } \\
\text { and is not reproducible. }\end{array}$ \\
\hline Hinz et al ${ }^{11}$ & $\begin{array}{l}\text { Management of Parkinson disease with organic cation } \\
\text { transporter optimization in a manner that allows for } \\
\text { management and control of all problems associated } \\
\text { directly and indirectly with L-dopa administration } \\
\text { during treatment. }\end{array}$ \\
\hline Hinz et $\mathrm{al}^{12}$ & $\begin{array}{l}\text { A paper written in response to an editor invitation. } \\
\text { The paper reviews a paper titled, "Non-validity and } \\
\text { clinical relevance of neurotransmitter testing". }\end{array}$ \\
\hline
\end{tabular}

the "spot baseline urinary neurotransmitter testing model" is not a model based on science, but is a business marketing tool, and a model formulated to drive laboratory sales of urinary monoamine assays. There is no original research published in scientific journals that discusses or defines the scientific foundation of the model. It is hereby asserted that the foundation upon which the model rests is clinically unproven. The alleged scientific foundation put forth in promotional sales material under this marketing model contradicts known science, especially in the areas of renal physiology and blood-brain barrier permeability.

There is no formal laboratory test known as the "urinary neurotransmitter testing". From an objective scientific perspective, the proper nomenclature for the relevant laboratory testing is "urinary monoamine assays". The monoamines, ie, serotonin, dopamine, norepinephrine, and epinephrine, do not function exclusively as neurotransmitters. They carry out other major neurotransmitter, neurohormonal, regulatory, autocrine, and paracrine functions. The monoamines found in the urine have not, do not, and will not function exclusively as neurotransmitters. Therefore, it is not appropriate to refer to urinary monoamine assays as "neurotransmitter testing" and ignore the other major functions of these monoamines in the body. ${ }^{15}$

Urinary monoamines exist in one of two states. The "endogenous state" is the normal day-to-day state. This occurs when a subject is taking no amino acids. The "competitive inhibition state" is found when significant amounts of both serotonin and dopamine amino acid precursors are being taken simultaneously. ${ }^{6,-11,13}$ This clinical review is undertaken exclusively to discuss the testing performed in the endogenous state with spot baseline urine samples.

The following applications are direct quotes from a laboratory website ${ }^{7}$ that is promoting some of the alleged attributes of the spot baseline urinary neurotransmitter marketing testing model. These include, but are not limited to:

- “.... baseline (urinary neurotransmitter) testing is the best approach to determine the neurotransmitter functional status of the central and peripheral nervous systems"

- "Administration of amino acid precursors directly impacts urinary monoamine levels; therefore, the results of monoamine assays merely need to be interpreted as being either high or low values with no need to make consideration for other forces impacting urinary monoamine levels between renal synthesis and showing up in the final urine"

- "Baseline testing of urinary monoamines prior to starting supplemental amino acid precursors is required in order to define the amino acid precursor starting dose needed in treatment" 
- "Baseline (urinary) monoamine assays in the absence of supplemental amino acid precursors are required to diagnose and define the serotonin and dopamine imbalance in the central and peripheral nervous systems"

- "Baseline (urinary) monoamine assays can serve as a reference point to gauge treatment effectiveness after amino acid precursors are started"

- "Baseline (urinary) monoamine assays can be used to reduce the risk of side effects when amino acid precursor treatment is started".

The "spot baseline urinary neurotransmitter testing marketing model" (herein referred to as "the marketing model") claims that the clinical applications for the test are based on science, yet when the alleged scientific claims supporting the marketing model are examined, they are contradicted by known science.

At present, the only clinically proven use for spot baseline urinary monoamine assays is as a screening test for pheochromocytoma or carcinoid syndrome to determine if a 24-hour urine test is needed to diagnose these diseases definitively. This application is hereby specifically excluded from consideration in this manuscript.

\section{Physician marketing claims}

Physicians and other caregivers are promoting sales of urinary monoamine assays under the "spot baseline urinary neurotransmitter testing marketing model" on the Internet. It is easy to find this type of advertising. This section discusses how some physicians were induced to promote this marketing model. The section ends with examples of marketing claims by physicians and caregivers currently found on the Internet.

This "spot baseline urinary neurotransmitter testing marketing model" has become known as the "pee in a cup and we will determine the neurotransmitter levels in your brain model". It is asserted that the alleged scientific statements driving sales of urinary monoamine assays are deceptively simple and intuitively seductive.

The actual science required to support or contradict "the marketing model" is found primarily in the renal physiology literature and blood-brain barrier permeability. It is asserted that this area of monoamine renal physiology is extraordinarily complex, especially for the uninitiated.

Physicians have implicit trust that the laboratory is giving accurately reported results and advice. For most physicians, this trust is cultivated by a history of dealing with only hospital and/or clinic-based laboratories under the medical direction of physicians who implement widely accepted treatment standards and testing policies. A basic flaw here is that the laboratories selling urinary monoamine assays under the "spot baseline urinary neurotransmitter testing marketing model" are not clinic-based or hospital-based. They are freestanding facilities directed and staffed by chemists who have no medical training or medical license. ${ }^{16-18}$

These laboratories are claiming, in their marketing, to have the expertise to tell physicians how to treat their patients, on a broad level, on the basis of the laboratory studies they perform. These laboratories provide "technical support" to assist physicians in treating their patients. The quality of this technical support raises concerns. Routine technical support is given by individuals with no formal medical training, no first-hand experience in patient care, and no medical licensure. In some cases, individuals with only a high-school degree, who are trained only from a marketing standpoint, advise physicians on how to treat their patients with clinically unproven methods in order to optimize sales of nutritional supplement products sold by the laboratory. While arguably it is the responsibility of the physician to implement or reject treatment advice, the whole concept of laboratory owners and employees with no firsthand patient care training, experience, or medical licensure, telling doctors how to treat their patients with clinically unproven methods may be construed as the unlicensed practice of medicine by unqualified individuals. At the very least it is a potential recipe for disaster. ${ }^{16-18}$

It is not hard to find physicians and other caregivers who are advertising the sale of urinary monoamine assays under the "spot baseline urinary neurotransmitter testing marketing model". Their numbers have grown in recent years. Some of the examples of Internet marketing of urinary monoamine assays under the "spot baseline urinary neurotransmitter testing marketing model" by physicians and other caregivers include the following assertions:

- "Neurotransmitter testing is now available to detect brain neurotransmitter imbalances"19

- "Neurotransmitter testing is used to detect imbalances in brain and body chemistry" 20

- "We now have (urinary neurotransmitter) laboratory tests that can accurately measure neurotransmitter levels and greatly simplify the task of developing a proper supplement plan, eliminating much of the guesswork and trial and error. They are also affordable and noninvasive in that they use a simple urine sample. A baseline test is usually critical to understanding a person's unique patterns and designing the most appropriate supplement program"21 
- “... approach is based on a baseline (urinary) measurement of your neurotransmitter and/or hormone levels. The initial testing of your levels from a urine or saliva sample constitutes your baseline"22

- "Neurotransmitter testing to detect brain neurotransmitter imbalances! Testing helps to determine exactly which neurotransmitter levels are out of balance and helps to determine which therapies are needed for an individualized treatment plan"23

- "For this to be most effective, it should include a specialized urinalysis test that provides a reliable means of measuring excretory values of neurotransmitters. The (name of company) neurotransmitter urinalysis panel can be utilized to establish baseline, therapeutic, and maintenance protocols" 24

- "Neurotransmitters are naturally occurring chemicals within the brain that relay signals between the nerve cells and are required for proper brain and body function. The approach is based on a baseline (urinary) measurement of your neurotransmitter and/or hormone levels". ${ }^{25}$

\section{Laboratory marketing claims}

This section discusses how the marketing model arrived at its current state, along with examples of the marketing claims made to fuel urinary monoamine testing. The marketing model is promoted primarily for disease states that have a high positive placebo effect. In many studies, attention deficit hyperactivity disorder and depression are associated with a positive placebo effect of $40 \%-50 \%,{ }^{5,9}$ Almost half of the patients with these diseases improve significantly in 1 month while being treated with placebo. However, under the marketing model, when this happens, those promoting the marketing model take credit for all cases that have improved. Because almost half of the patients show significant improvement within 1 month, there is little upon which to challenge the veracity of the laboratory claims of treatment efficacy for the average physician not aware of the placebo statistics. Indeed, physicians have said under questioning, "I like this approach; at least half of my patients get better in the first month". This approach completely ignores the placebo effect while quietly exploiting it in the background for the marketing of urinary monoamine assays. ${ }^{5,9}$

Virtually any properly licensed laboratory can perform urinary monoamine assays. It is the clinical applications promoted for these urinary monoamine assays that differentiate one laboratory from another. The following are direct quotes from urinary monoamine assay marketing under the urinary neurotransmitter marketing model.
A 2007 marketing paper noted, "Studies have demonstrated intact neurotransmitter transport out of the CNS, into the periphery, via blood-brain barrier transporters. Renal filtration of neurotransmitters via specific transporters is welldocumented. Researchers have provided examples of urinary neurotransmitter measurements that correlate with CNS (central nervous system) tissue concentrations". ${ }^{26}$

On September 22, 2010, a laboratory website ${ }^{27}$ promoting and selling urinary monoamine assay under the spot baseline urinary neurotransmitter testing marketing model on the Internet noted that baseline testing is recommended with regard to urinary monoamine assays in marketing for all neurotransmitter-related conditions for several reasons:

- "First, it reveals imbalances that may be present in the nervous system, thereby establishing a quantitative need for intervention. Symptoms alone often do not provide the information needed to effectively target the underlying neurotransmitter imbalances"

- "Next, baseline testing allows for more informed decisions to be made regarding intervention selection"

- "With neurotransmitter data in hand, practitioners can choose products that target neurotransmitter imbalances"

- "Likewise, neurotransmitter testing shows which interventions may not be suitable for a particular individual, reducing the chance of unwanted side effects"

- "Finally, the baseline test provides an important reference point to monitor the effects of therapy. Retests can be compared to baseline data to evaluate progress made in the restoration process"

- "In addition to baseline testing, periodic retesting is used to indicate a need for change in a patient's dosing regimen".

The websites of other laboratories have posted the following on their web pages supporting sales of urinary monoamine assays under the spot baseline urinary neurotransmitter testing marketing model:

- "(Company name) line of formulas designed to address the communication system imbalances found through testing. TNT formulations may be used as anchor products during the initial therapeutic phase, following a baseline (urinary) test" ${ }^{\prime 28}$

- "For this to be most effective, it should include a specialized urinalysis test that provides a reliable means of measuring excretory values of neurotransmitters. From those findings an individualized protocol including transdermal amino acid supplementation is devised to improve the quantity and ratios of neurotransmitters in the 
brain. The first step is to identify baseline (urinary) neurotransmitter levels" ${ }^{2}$

- "The optimal range is suggested for the interpretation of baseline (urinary neurotransmitter testing) values. If neurotransmitter values fall above or below the optimal range, your nervous system may be out of balance"29

- "In support of urinary neurotransmitter assessment, studies have demonstrated that intact neurotransmitter is transported from the CNS to the periphery, via specific BBB transporters, followed by renal filtration of neurotransmitters with subsequent excretion in the urine". ${ }^{30}$

\section{Scientific issues}

There is a highly polarized divergence between published peer-reviewed science and the "spot baseline urinary neurotransmitter testing marketing model". In this section we discuss the key points of this divergence. In order to enable the reader to sort out which claims from caregivers and laboratories are correct, it is important to identify and discuss the scientific foundation the marketing model is resting on. The validity of the spot baseline urinary neurotransmitter testing marketing model used to promote sales of urinary monoamine assays rests on correct answers to the following questions. What is the permeability of the blood-brain barrier regarding the monoamines under normal conditions? Are significant amounts of monoamines found in the final urine synthesized by kidney structures under normal conditions? What is the level of reproducibility of urinary monoamine testing results from the same subject on a day-to-day basis?

\section{Blood-brain barrier permeability}

Some variations of "the marketing model" rest on claims that measurement of urinary monoamines has a direct relationship with the monoamine levels found in the brain. This gives rise to the concept "pee in a cup and we will determine the neurotransmitter levels of your brain model".

Two specific considerations exist in the marketing model when claiming that monoamines cross the blood-brain barrier. The first assumption is that monoamines found in the final urine contain monoamines that have been in the central nervous system. The second requirement is that the monoamines in the final urine are in constant equilibrium with the monoamines found in the central nervous system and peripheral nervous system. Embodied in the marketing model is the concept that monoamines must cross the bloodbrain barrier then come to equilibrium with the peripheral nervous system and final urine, leading to one large pool of monoamines in constant equilibrium throughout the body.
The idea that monoamines do not cross the blood-brain barrier under normal conditions has been widely accepted in science for over 60 years. This fact has been referenced heavily over time, as noted in the sampling of 104 references noted in support of the following four bullet points:

- "Serotonin does not cross the blood-brain barrier"5-7,31-69

- "Dopamine does not cross the blood-brain barrier"70-93

- "Norepinephrine does not cross the blood-brain barrier"94-107

- "Epinephrine does not cross the blood-brain barrier". ${ }^{108-131}$ In order for claims made under the spot urinary neurotransmitter testing marketing model to be valid, monoamines must cross the blood-brain barrier. This is contrary to the over 100 references cited above. When those promoting the original laboratory marketing model, which is still promoted by some today, became cognizant that these monoamines did not freely cross the blood-brain barrier, the model began to change. The new marketing argument asserts that transporters move monoamines across the blood-brain barrier in amounts significant enough to affect equilibrium between the central nervous system, peripheral nervous system, and final urine. It continues to be asserted that monoamines in the final urine are composed of monoamines that have been in the central nervous system. ${ }^{30}$

A review of transporter physiology is in order. The monoamines are primarily transported by organic cation transporters (OCT). ${ }^{132}$ It is recognized that the OCT of the liver, intestines, kidneys, and brain are "identical and homologous". ${ }^{133}$ In 2010, the authors of this paper published the most recent refinement to the monoamine OCT model. ${ }^{6}$

Even if there were transporters that transported monoamines out of the brain to the peripheral nervous system, there would be no equilibrium or direct relationship, as asserted by the marketing model, between the central nervous system, peripheral nervous system, and final urine. The amounts of monoamines that are transported vary greatly over time. During transport, OCT affect monoamine gradients where the amount of monoamine on one side of the transporter is not the same as the amount on the other side of the transporter. In addition, monoamine concentrations on either side of the transporter rise and fall independent of each other. This leads to a situation where if transport did occur, the monoamines in the central nervous system are not in equilibrium and do not share a direct relationship with levels in the peripheral nervous system and final urine, as alleged by the marketing model. ${ }^{6}$

In the transporter version of the marketing model, the laboratories involved continue to assert that urinary 
monoamine levels correlate with monoamines in the central nervous system and are a measurement of monoamines that have been in the central nervous system. ${ }^{7,19-30}$ A published discussion of blood-brain barrier transport under one of the current marketing models written by the staff of a laboratory selling under the marketing model appeared in a 2010 review article (ie, no original research was reported) published by a psychology journal that had decided it had the expertise to publish on peer-reviewed issues relating to monoamine renal physiology and blood-brain barrier physiology. ${ }^{30}$ Figure 1 accompanying that review is a reproduction from Ohtsuki. ${ }^{134}$ The article claimed that both illustrations represent transport of monoamines across the blood-brain barrier. Close examination of the reference shows that the assertions of Ohtsuki are contrary to the psychology review article in noting that there is no known mechanism for these monoamines that transports them across the blood-brain barrier. The only thing that the figures from these two articles illustrate is how the monoamines are transported into the endothelial cells of the blood-brain barrier where they affect regulation and that the monoamines are not transported across the blood-brain barrier. ${ }^{30,134}$

There is no peer-reviewed published research that supports the marketing model versions which expound that, under normal conditions, monoamines cross the blood-brain barrier and are in equilibrium with the peripheral nervous system, urinary monoamine assays are of monoamines that have been in the brain, and assays of monoamines found in the final urine have a direct relationship with levels found in the brain. There is no scientific support for any of these propositions.

\section{Source of urinary monoamines}

The second major issue reviewed is "the source of synthesis of monoamines found in the urine under normal conditions". The selling of urinary monoamine assays under the "the marketing model" has made no scientific room for the possibility that a significant source of synthesis of the monoamines found in the final urine is from sources other than the peripheral or central nervous systems. The marketing model claim is that urinary monoamines found in the final urine are monoamines filtered at the glomerulus, and measurement of monoamines in the final urine is a direct assay of the monoamines of the peripheral and/or central nervous systems. The marketing model fails to account for known scientific facts that are contrary to these assertions. ${ }^{30}$

Science notes that significant amounts of monoamines found in the urine, under normal conditions, have never been in the central and/or peripheral nervous systems. The final urine, under normal conditions, is composed of significant amounts of monoamines synthesized by structures found in the kidneys. The following referenced statements support this set of facts:

- "Most of the serotonin or dopamine found in the urine is synthesized in the kidney. Therefore, the excreted neurotransmitters must be synthesized in the kidneys and escape reabsorption into the blood in order to be excreted in the urine" 14

- "These findings provide further evidence that the increase in urine serotonin after administration of both serotonin precursors (5-HTP; glu-5-HTP) is largely due to serotonin synthesized within the kidney"135

- “... free urine serotonin reflects actual biosynthesis by the kidney" 136

- "These results are consistent with the intrarenal formation of serotonin by renal decarboxylase with attendant alterations in renal hemodynamics and salt and water excretion" 137

- "Dopamine and serotonin in the urine are believed to reflect mainly the tubular decarboxylation of filtered or circulating L-dopa and L-5-HTP, respectively"138

- "Intrarenal dopamine (3,4-dihydroxyphenethylamine; DA) and serotonin (5-hydroxytryptamine; 5-HT) are synthesized abundantly by renal proximal tubular cells from L-3,4dihydroxyphenylalanine and 5-hydroxy-L-tryptophan, respectively" ${ }^{\prime 39}$

- "These data indicate that urinary free dopamine is mainly derived from plasma dopa, which is converted by dopa decarboxylase in the kidney"140

- "Urinary dopamine excretion was not diminished by sympathectomy, was increased by L-dopa (but not tyrosine or dopamine 4-Osulphate) in the perfusate and was virtually abolished by prior treatment with the dopa decarboxylase inhibitor, carbidopa. These results confirm the importance of renal extraneuronal dopamine production, from circulating L-dopa, as a contributor to urinary dopamine excretion"141

- "The data indicates that urinary free dopamine in a high sodium diet is mainly derived from the renal tubular cells"142

- "Plasma dopa is the main source of urinary dopamine"143

- "All of the components of a complete dopamine system are present within the kidney"144

- "It is concluded that (urinary) dopamine and serotonin are accumulated and likely formed within proximal convoluted tubular cells"145 


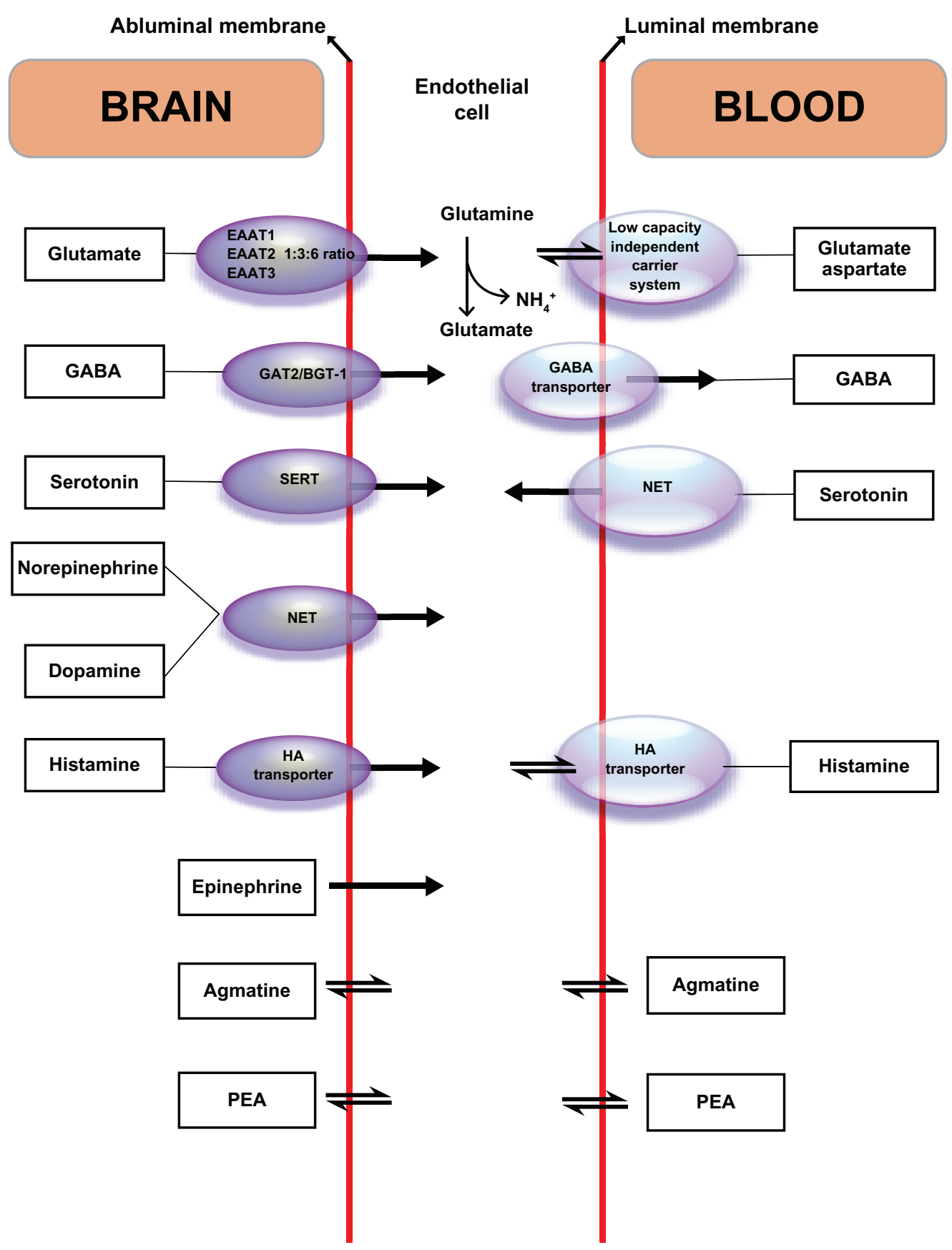

Figure I Serotonin, dopamine, norepinephrine, and epinephrine are transported across the abluminal membrane surface of the blood-brain barrier into the endothelial cells where they affect regulatory function. They do not cross the blood-brain barrier since they do not cross the luminal membrane.

Reprinted from Neuroscience \& Biobehavioral Reviews, Vol 35, Issue 3, Marc et al, Neurotransmitters excreted in the urine as biomarkers of nervous system activity: Validity and clinical applicability, p 635-644, Copyright 201 I, with permission from Elsevier.

Abbreviations: EAAT, excitatory amino acid transporter; GABA, $\gamma$-aminobutyric acid; GAT2/BGT-I, GABA/betaine transporter; HA, histamine; NET, norepinephrine transporter; PEA, phenylethylamine; SERT, serotonin transporters.

- “... (urinary) dopamine is phosphaturic and is synthesized by kidney proximal tubule"146

- “... urinary norepinephrine is not solely derived from plasma by glomerular filtration but also arises from an unidentified renal source"147

- “... the renal nerves were the main sites of the (urinary) norepinephrine synthesis" ${ }^{\prime 148}$
- "Perfusion of L-dopa and free dopamine led to the generation of norepinephrine in the kidney. This synthesis was abolished when the kidney was denervated, suggesting that the renal nerves were the main sites of the (urinary) norepinephrine synthesis"148

- "Several recent studies have demonstrated that dopamine can be generated from L-dopa in the isolated perfused 
rat kidney, and those findings led to the conclusion that most of the urinary dopamine could be derived from circulating L-dopa (in the kidneys)" "148

- "Recent studies from our laboratory have suggested that urinary NE (norepinephrine) may be derived, in part, from intrarenal sources in man"149

- "We have previously reported that in standing humans a significant portion of urinary norepinephrine is derived from processes other than glomerular filtration"149

- "Net production was observed for NE (norepinephrine), DA (dopamine), and NM (normetanephrine) in the renal metabolic compartment, suggesting that a portion of these compounds excreted in the urine may result from intrarenal synthesis or metabolism of these materials"149

- “... urinary epinephrine may not simply be filtered from the bloodstream" and "urinary epinephrine was derived from the kidney"150

- "We conclude that appreciable portions of renal and urinary epinephrine are synthesized in the kidney by an enzyme distinct from PNMT". ${ }^{151}$

In reviewing the validity of the "spot baseline urinary neurotransmitter testing marketing model" it is important to determine what is being assayed and where it came from. The first assertion of the model claims that it is urinary neurotransmitters that are being assayed. Considering the neurohormonal, regulatory, paracrine, and autocrine functions of monoamines, the monoamine population found in the urine has not exclusively functioned as neurotransmitters. This marketing model hinges on claims that the final urine is composed of monoamines that have functioned only as neurotransmitters, which have crossed the blood-brain barrier, and have been simply filtered at the glomerulus, and then excreted directly into the final urine. Therefore, the marketing model, has assumed that there is constant equilibrium between the monoamines of the central and peripheral nervous systems and the monoamines found in the final urine which have allegedly only functioned as neurotransmitters. This marketing model is simply not valid. There is no direct relationship between monoamines in the final urine and monoamines in the peripheral or central nervous systems, and under normal conditions, significant amounts of monoamines found in the final urine have not been in the peripheral or central nervous systems, but have been newly synthesized by structures in the kidneys.

\section{Day-to-day reproducibility of assays}

The reproducibility of testing techniques in the laboratory, as commonly addressed by precision and accuracy studies, is not what is being discussed here. It is the reproducibility of urinary monoamine assay results obtained from the same subject from one day to the next that is under discussion. It would appear that none of the laboratories selling urinary monoamine testing under this marketing model bothered to verify the day-to-day reproducibility of testing in the same subject. The authors of this paper published multiple original research papers where the topic was "matched-pairs $t$-test" analysis of baseline monoamine assays performed on different days from the same subject. Each matched pair was made up of a urine sample obtained from a subject on one day (test 1) paired with a urine sample from the same subject on a different day (test 2). These test 1 and test 2 matched pairs were then grouped and analyzed using the "matched-pairs $t$-test". It was found that the urinary level of all four monoamines (serotonin, dopamine, norepinephrine, and epinephrine) between test 1 and test 2 for the group differed significantly from day to day $(P<0.05)$. The amount of each monoamine found in test 1 and test 2 urine samples was not consistent and reproducible on a day-to-day basis in the same individual. ${ }^{7,10}$ The following statement illustrates the impact of this finding: "It is asserted that if one hundred baseline urinary monoamine assays from the same subject were obtained on one hundred different days, one hundred different laboratory values would be reported. In the process, no firm reproducible laboratory data from one day to another day would be generated and no reliable clinical decision making could occur using this type of data" ${ }^{7,10}$ These findings invalidate the ability to use "baseline monoamine assays" for anything more than a coarse screening tool, under the only clinically proven applications known, for monoamine hyperexcreting tumors, ${ }^{7,10}$ which is something we are not discussing in this paper.

\section{Unproven science of biomarkers}

The alleged scientific foundation of the marketing model continues to change. The marketing model still continues to assert that all of the urinary monoamines found in the final urine under normal conditions have been in the peripheral and central nervous systems, despite the overwhelming peer-reviewed published research evidence to the contrary. The marketing model now asserts that urinary monoamines can be used as biomarkers of common diseases, such as attention deficit hyperactivity disorder and depression, although these claims are clinically unproven with no published original research that would support or define treatment of the individual patient in clinic. The only published original research on the topic discredits the biomarker approach for several of the reasons already discussed in this paper, not the 
least of which is the lack of day-to-day consistency of test results in the same subject. ${ }^{30}$

The business model for the marketing of urinary monoamine assays as biomarkers of disease has certainly arrived. The most extensive writing on the topic is a 2010 literature review found in a psychology journal and containing no original research. ${ }^{30}$ Contrary to the claims of the biomarker marketing model cited, ${ }^{30}$ the final urine being assayed contains significant amounts of urinary monoamines synthesized by the kidneys. The actual monoamine levels found in the final urine when corrected for specific gravity considerations by use of the monoamine to creatinine ratio which compensates for dilution of the urine, is an assay of the forces within the kidneys that impact the monoamines between synthesis and the final urine. The OCTN2 transporters of the apical surface and the OCT2 transporters of the basolateral surfaces of the proximal convoluted renal tubule cells have a major impact on monoamine concentrations found in the final urine. ${ }^{13}$ The marketing model is silent on this interaction.

The most recent review of urinary biomarker applications had numerous references citing group results of urinary monoamine trends. The authors then made the jump, without proper studies in place, to asserting that these group results are valid for use in treatment of individual patients in the clinical setting. ${ }^{30}$ Group study results cannot be used or equated to treatment parameters in an individual. Even if a group trend was found for a specific disease, the day-to-day significant changes in urinary monoamine assays from the same individual would invalidate the clinical applications of the group trend finding. ${ }^{7,10}$

The question is raised, "What is the possible impact to the medical community of laboratories selling clinically unproven urinary biomarker tests?" One of the references cited in the bibliography of the 2010 biomarker review paper ${ }^{30}$ notes the following:

"Perhaps most worrisome is the problem of premature clinical application (of biomarkers), both because of the risk for harm to patients (misdirected in treatment decisions) and for the cynicism about biomarkers in general this engenders; still, the need for useful biomarkers is so great that sometimes enthusiasm and optimism may overtake consideration of results from carefully conducted controlled clinical trials. To paraphrase the film Jerry Maguire, 'show me the data!' must be the watchword if clinicians are to make prudent choices for their patients". ${ }^{152}$

The authors of this paper assert that the statement immediately above, in citing "premature clinical applications" of biomarker testing, ${ }^{152}$ are discussing the exact problem associated with the urinary monoamine marketing model of biomarkers at this time. Careful review of the references cited revealed no definitive clinical trials or support regarding use of spot baseline urinary neurotransmitter testing in biomarker applications for treatment of individuals in the clinical setting. The statement referenced above is correct in that premature use of an unproven biomarker application can risk causing harm to the patient. Examples of the harm supported under the statement include ${ }^{152}$ but are not limited to:

- A diagnosis of a false normal state when disease exists

- Misdiagnosis of disease states

- Medical treatment decisions that make the disease state worse

- Initiation of unnecessary treatment

- Delay in implementing available beneficial treatment

- False hope given where no hope exists, leading to distress when this is realized

- Interference with the doctor-patient relationship when expected results promoted by the laboratory do not turn out as advertised due to unrealistic expectations of care.

\section{Conclusion}

The "spot baseline urinary neurotransmitter testing marketing model" used to promote sales of urinary monoamine assays is not valid and has no scientific foundation. For the claims of the marketing model to be valid, monoamines would need to cross the blood-brain barrier and be in constant equilibrium with the peripheral nervous system and final urine. As demonstrated by at least 100 citations, these monoamines do not cross the blood-brain barrier. While one version of the marketing model seems to recognize this and asserts that the monoamines are transported out of the central nervous system, the very literature cited in making these transporter assertions specifically illustrates that monoamines are not transported out of the central nervous system to the peripheral nervous system. For the marketing model to be valid, monoamines found in the final urine need to be composed primarily of the monoamines from the peripheral system that are merely filtered and placed in the final urine as claimed. A significant amount of monoamines found in the final urine are synthesized by the kidneys. These monoamines perform other major functions in the body. Therefore, identifying and calling these monoamine assays of the final urine, "neurotransmitter testing" is not appropriate.

For the marketing model to be valid, urinary monoamine assays obtained from the same subject need to be consistent from one day to the next $(P>0.05$ on the "matched-pairs 
$t$-test" using paired samples from the same subject obtained on different days). Previous published literature indicates that this is not the case; urinary monoamines differ significantly from day to day in the same subject.

The bottom line is that the "spot baseline urinary neurotransmitter testing marketing model" used to sell urinary monoamine assays has not been clinically proven. The original scientific research supporting the model, if it exists, cannot be found in published science. It is postulated that after 10 years of using this marketing model to sell urinary monoamine assays it would be helpful if the first original research scientific peer-reviewed paper outlining the foundation of the model would be formally written in order to subject it to appropriate peer review.

It is the goal of this writing to spark interest and dialog on the validity of the "spot baseline urinary neurotransmitter testing marketing model" used in support of urinary monoamine assay sales. We hope that those using this marketing model directly or indirectly in patient care will come forth and enter into meaningful dialog. It is suggested that those promoting this marketing model publish their original research findings in order to facilitate a proper scientific dialog on the topics of monoamine renal physiology and blood-brain barrier permeability in relation to marketing claims.

\section{Disclosure}

MH discloses ownership of NeuroResearch Clinics Inc. TU discloses laboratory directorship of DBS Laboratories, Duluth, MN.

\section{References}

1. Sanesco International. Available from: http://www.sanesco.net/ practitioner-information/targeted-nutritional-therapy/34. Accessed May 14, 2011.

2. Sabre Sciences Inc. Available from: http://www.atlanticnature.net/df/ atlanticnature/hormone.pdf. Accessed May 14, 2011.

3. Neurogistics Inc. Available from: http://www.neurogistics.com/ TheProgram/index_body.asp. Accessed May 14, 2011.

4. NeuroScience Inc. Technical guide. 4th ed, May, 2006. Available from: https://www.neurorelief.com/images/Education/TechGuide/ techguide-may06.pdf. Accessed May 14, 2011.

5. Hinz M. Depression. In: Kohlstadt I, editor. Food and Nutrients in Disease Management. Boca Raton, FL: CRC Press; 2009.

6. Hinz M, Stein A, Uncini T. The dual-gate lumen model of renal monoamine transport. Neuropsychiatr Dis Treat. 2010;6:387-392.

7. Hinz M, Stein A, Trachte G, Uncini T. Neurotransmitter testing of the urine; a comprehensive analysis. Open Access Journal of Urology. 2010;2:177-183.

8. Hinz M, Stein A, Uncini T. A pilot study differentiating recurrent major depression from bipolar disorder cycling on the depressive pole. Neuropsychiatr Dis Treat. 2010;6:741-747.

9. Hinz M, Stein A, Uncini T. Treatment of attention deficit hyperactivity disorder with monoamine amino acid precursors and organic cation transporter assay interpretation. Neuropsychiatr Dis Treat. 2011;7: 31-38.
10. Hinz M, Stein A, Uncini T. Urinary neurotransmitter testing: considerations of spot baseline norepinephrine and epinephrine. Open Access Journal of Urology. 2011;3:19-24.

11. Hinz M, Stein A, Uncini T. Amino acid management of Parkinson disease: a case study. Int J Gen Med. 2011;4:1-10.

12. Hinz M, Stein A, Uncini T. Non-validity and clinical relevance of neurotransmitter testing.

13. Stein A, Hinz M, Uncini T. Amino acid responsive Crohn's disease, a case study. Clin Exp Gastroenterol. 2010;3:171-177.

14. Trachte G, Uncini T, Hinz M. Both stimulatory and inhibitory effects of dietary 5-hydroxytryptophan and tyrosine are found on urinary excretion of serotonin and dopamine in a large human population. Neuropsychiatr Dis Treat. 2009:227-235.

15. Bogaard H, Abe K, Vonk Noordegraaf A, Voelkel NF. The right ventricle under pressure cellular and molecular mechanisms of right-heart failure in pulmonary hypertension. Chest. 2009;135:794-804.

16. NeuroScience Inc. Available from: https://www.neurorelief.com/index. php? $\mathrm{p}=\mathrm{cms} \& \mathrm{cid}=47 \& \mathrm{pid}=0$. Accessed May 14, 2011.

17. Sanesco International. Available from: http://www.sanesco.net/ practitioner-information/clinical-technical-support. Accessed May 14, 2011.

18. Neurogistics. Available from: http://www.neurogistics.com/Clinician SpecificIn0949.asp. Accessed May 14, 2011.

19. Integrative Psychiatry. Available from: http://www.integrativepsychiatry. net/neurotransmitter_tests.html. Accessed May 14, 2011.

20. Ten Penny Health Medicine. Available from: http://www.tenpennyimc. com/viewpage.aspx?pagename $=$ neurotransmitter_testing $\% 20 \% 20 \&$ CurNavId=153. Accessed May 14, 2011.

21. Natural Health Solutions. Available from: http://doctorvolpe.com/ anxiety-and-depression. Accessed May 14, 2011.

22. Holistic Naturopathic Centre. Available from: http://www. holisticnaturopath.com/neurotrans.htm. Accessed May 14, 2011.

23. Carol Perkins. Neurotransmitter testing to detect brain neurotransmitter imbalances. Available from: http://www.ndaccess.com/NaturalChoices/ PageNew.asp?PageID=21. Accessed May 14, 2011.

24. Future of Wellness. Available from: http://www.futureofwellness.net/ neuroendrocrin.html. Accessed May 14, 2011.

25. Online Wellness Community. Natural alternative to balancing your brain chemistry to treat depression, anxiety and ADD. Available from: http://www.onlinewellnesscommunity.org/blog/2011/02/naturalalternative-to-balancing-your-brain-chemistry-to-treat-depressionanxiety-and-add-dr-bronner-handwerger Accessed May 14, 2011.

26. Alts J, et al. Urinary neurotransmitter testing: myths and misconceptions. Oseola, WI: NeuroScience Inc; 2007.

27. NeuroScience Inc. Available from: https://www.neurorelief.com/index. php?option $=$ com_content $\&$ task $=$ view\&id=131\&Itemid $=48$. Accessed September 22, 2010.

28. Sanesco International. Available from: http://www.sanesco.net/ practitioner-information/glossary. Accessed May 14, 2011.

29. NeuroScience Inc. Available from: http://www.modernherbalist.com/ brochures/neurotransmitters101-brochure.pdf. Accessed May 14, 2011.

30. Marc D, Ailts JW, Campeau DC, Bull MJ, Olson KL. Neurotransmitters excreted in the urine as biomarkers of nervous system activity: validity and clinical applicability. Neurosci Biobehav Rev. 2011;35: 635-644.

31. Klee G, Bertino J, Callaway E. Clinical studies with LSD-25 and two substances related to serotonin. J Ment Sci. 196;106:301-308.

32. Garattini S, Valzelli L. Serotonin. Amsterdam, The Netherlands: Elsevier; 1965.

33. Krikorian A. The psychedelic properties of banana peel: an appraisal. Econ Bot. 1968;22:385-389.

34. Glassman A. Indole amines and affective disorders. Psychosom Med. 1969:31.

35. Plonk J, Feldman J. Adrenal function in the carcinoid syndrome: effects of the serotonin antagonist cyproheptadine. Metabolism. 1975;24: $1035-1046$. 
36. Sabelli HC, Mosnaim AD, Vazquez AJ. Biochemical plasticity of synaptic transmission: a critical review of Dale's principle. Biol Psychiatry. 1976;11:481-524.

37. Ferrari C, Caldara R, Rampini P, et al. Inhibition of prolactin release by serotonin antagonists in hyperprolactinemic subjects. Metabolism. 1978;27:1499-1504

38. Loizou L. Uptake of monoamines into central neurones and the bloodbrain barrier in the infant rat. Br J Pharmacol. 1970;40:800-813.

39. Gill D, Clarke M. Early controlled trials. BMJ. 1966;312:1298.

40. Garfinkel P, Warsh J, Stancer H, et al. CNS monoamine metabolism in bipolar affective disorder. Evaluation using a peripheral decarboxylase inhibitor. Arch Gen Psychiatry. 1977;34:735-739.

41. Piggott L. Overview of selected basic research in autism. JAutism Dev Disord. 1979;9:199-216.

42. Millhorn D, Eldridge F, Waldrop R. Prolonged stimulation for respiration by endogenous central serotonin. Respir Physiol. 1980;42: 171-188.

43. Pollock, J, Rowland N. Peripherally administered serotonin decreases food intake in rats. Pharmacol Biochem Behav. 1981;15:179-183.

44. Israngkun P, Newman HA, Patel ST, Duruibe VA, Abou-Issa H. Potential biochemical markers for infantile autism. Chem Neuropathol. 1986;5:51-70.

45. Calogero A, Bernardini R, Margioris A. Effects of serotonergic agonists and antagonists on corticotropin-releasing hormone secretion by explanted rat hypothalami. Peptides. 1989;10:189-200.

46. Amenta F, Zaccheo D, Collier W. Neurotransmitters, neuroreceptors and aging. Mech Ageing Dev. 1991;61:249-273.

47. Mann JJ, McBride PA, Brown RP, et al. Relationship between central and peripheral serotonin indexes in depressed and suicidal psychiatric inpatients. Arch Gen Psychiatry. 1992;49:442-446.

48. Wise S. Clinical studies with fluoxetine in obesity. Am J Clin Nutr. 1992;55:181S-184S.

49. Polidori C, Zeng Y, Zaccheo D, et al. Age-related changes in the visual cortex: a review. Arch Gerontol Geriatr. 1993;17:145-164.

50. Pij1 H, Toornvliet A, Meinders A, Leuven JA, Van Kempen CM. Low serum cholesterol and serotonin metabolism. Results may have been affected by confounding. BMJ. 1996;312:221.

51. Oliveira V, Moreira E, Farah VD, Consolim-Colombo F, Krieger EM, Irigoyen MC. Cardiopulmonary reflex impairment in experimental diabetes in rats. Hypertension. 1999;34:813-817.

52. Siu L, Chapman W, Moore M. Use of the somatostatin analogue octreotide acetate in the treatment of encephalopathy associated with carcinoid tumor: case report. Am J Clin Oncol. 1997;20:558-561.

53. Carley D, Radulovacki M. Role of peripheral serotonin in the regulation of central sleep apneas in rats. Chest. 1999;115:1397-1401.

54. Portas C, Bjorvatn B, Ursin R. Serotonin and the sleep/wake cycle: special emphasis on microdialysis studies. Prog Neurobiol. 2000;60: 13-35.

55. Carley D, Depoortere H, Radulovacki M. R-zacopride, a 5-HT3 antagonist/5-HT4 agonist, reduces sleep apneas in rats. Pharmacol Biochem Behav. 2001;69:283-289.

56. Berry R, Hayward L. Selective augmentation of genioglossus electromyographic activity by 5-hydroxytryptophan in the rat. Pharmacol Biochem Behav. 2003;74:877-882.

57. Gupta A, Silman A. Psychological stress and fibromyalgia: a review of the evidence suggesting a neuroendocrine link. Arthritis Res Ther. 2003;6:98-106.

58. Pyle A, Argyropoulos S, Nutt D. The role of serotonin in panic: evidence from tryptophan depletion studies. Acta Neuropsychiatr. 2004;16: 79-84.

59. Berry R, Koch G, Hayward L. Low-dose mirtazapine increases genioglossus activity in the anesthetized rat. Sleep. 2005;28:78-84.

60. Jones D, Story A. Serotonin syndrome and the anaesthetist. Anaesth Intensive Care. 2005;33:181-187.

61. Whitaker-Azmitia P. Behavioral and cellular consequences of increasing serotonergic activity during brain development: a role in autism? Int J Dev Neurosci. 2005;23:75-83.
62. Li Y, Kerr B, Kidd M, Gonyou HW. Use of supplementary tryptophan to modify the behavior of pigs. J Anim Sci. 2006;84:212-220.

63. Shattock P, Whiteley P. The role of tryptophan in autism and related disorders. Nutrition Practitioner. 2006;1-9.

64. Carley D, Olopade C, Ruigt G, Radulovacki M. Efficacy of mirtazapine in obstructive sleep apnea syndrome. Sleep. 2007;30:35-41.

65. Zhao Z, Chiechio S, Sun YG, et al. Mice lacking central serotonergic neurons show enhanced inflammatory pain and an impaired analgesic response to antidepressant drugs. J Neurosci. 2007;27:6045-6053.

66. Makkonen I, Raili Riikonen R, Kokki H, Airaksinen MM, Kuikka JT. Serotonin and dopamine transporter binding in children with autism determined by SPECT. Dev Med Child Neurol. 2008;50:593-597.

67. Yadav V, Ryu J, Suda N, et al. Lrp5 controls bone formation by inhibiting serotonin synthesis in the duodenum. Cell. 2008;135:825-837.

68. Wulsin L, Musselman D, Otte C, et al. Depression and whole blood serotonin in patients with coronary heart disease from the Heart and Soul Study. Psychosom Med. 2009;71:260-265.

69. Kobayashi T, Hasegawa H, Kaneko E, Ichiyama A. Gastrointestinal serotonin: depletion due to tetrahydrobiopterin deficiency induced by 2,4-diamino-6-hydroxypyrimidine administration. J Pharmacol Exp Ther. 2010;298:G692-G699.

70. Fangman A, O'Malley W. L-dopa and the patient with Parkinson's disease. Am J Nurs. 1969;69:1455-1457.

71. Srimal R, Dhawan B. An analysis of methylphenidate induced gnawing in guinea pigs. Psychopharmacologia. 1970;18:99-107.

72. Leon A, Spiegel H, Thomas G, Abrams WB. Pyridoxine antagonism of levodopa in parkinsonism. JAMA. 1971;218:1924-1927.

73. Smythe G, Edwards G, Graham P, Lazarus L. Biochemical diagnosis of pheochromocytoma by simultaneous measurement of urinary excretion of epinephrine and norepinephrine. Clin Chem. 1992;38: 486-492.

74. Verde G, Oppizzi G, Colussi G, et al. Effect of dopamine infusion on plasma levels of growth hormone in normal subjects and in acromegalic patients. Clin Endocrinol. 1976;5:419-423.

75. Weiner R, Ganong W. Role of brain monoamines and histamine in regulation of anterior pituitary secretion. Physiol Rev. 1978;58: 905-976.

76. Quinn N. Fortnightly review: drug treatment of Parkinson's disease. BMJ. 1995;310:575

77. Mason L, Cojocaru T, Cole D. Surgical intervention and anesthetic management of the patient with Parkinson's disease. Int Anesthesiol Clin. 1996;34:133-150.

78. Volkow N, Fowler J, Gatley S, et al. PET evaluation of the dopamine system of the human brain. J Nucl Med. 1996;37:1242-1256.

79. Checkley S. Neuroendocrine tests of monoamine function in man: a review of basic theory and its application to the study of depressive illness. Psychol Med. 1980;10:35-53.

80. Nishino T, Lahiri S. Effects of dopamine on chemoreflexes in breathing. J Appl Physiol. 1981;50:892-897.

81. Pollock, J, Rowland N. Peripherally administered serotonin decreases food intake in rats. Pharmacol Biochem Behav. 1981;15: 179-183.

82. Greenamyer J. Glutamate-dopamine interactions in the basal ganglia: Relationship to Parkinson's disease. J Neural Transm Gen Sect. 1993; 91:255-269.

83. Ward S, Bellville J. Effect of intravenous dopamine on hypercapnic ventilatory response in humans. J Appl Physiol. 1983;55: $1418-1425$.

84. Morton J, Connell J, Hughes M, et al. The role of plasma osmolality, angiotensin II and dopamine in vasopressin release in man. Clin Endocrinol (Oxf). 1985;23:129-138.

85. Seri I, Tulassay T, Kiszel J, et al. Effect of low-dose dopamine infusion on prolactin and thyrotropin secretion in preterm infants with hyaline membrane disease. Biol Neonate. 1985;47:317-22.

86. Al-Damluji S, Rees L. Effects of catecholamines on secretion of adrenocorticotrophic hormone (ACTH) in man. J Clin Pathol. 1987; 40:1098-1107. 
87. Hoffman B, Lefkowitz R. Catecholamines and sympathomimetic drugs. In: Gillman AG, Rall TW, Nies AS, Taylor P, editors. Goodman and Gillman's The Pharmacological Basis of Therapeutics. New York, NY: Pergamon Press; 1990.

88. Levein N, Thorn S, Wattwil M. Dopamine delays gastric emptying and prolongs orocaecal transit time in volunteers. Eur J Anaesthesiol. 1999;16:246-250.

89. Bell D, McLellan T, Sabiston C. Effect of ingesting caffeine and ephedrine on 10-km run performance. Med Sci Sports Exerc. 2002;34: 344-349.

90. Bergerot A, Storer R, Goadsby P. Dopamine inhibits trigeminovascular transmission in the rat. Ann Neurol. 2007;61:251-262.

91. Scanlon M, Weightman D, Shale D, et al. Dopamine is a physiological regulator of thyrotrophin $(\mathrm{TSH})$ secretion in normal man. Clin Endocrinol (Oxf). 2008;1:7-15.

92. Allen G, Land J, Heales S. A new perspective on the treatment of aromatic L-amino acid decarboxylase deficiency. Mol Genet Metab. 2009;97:6-14.

93. Rubí B, Maechler P. Minireview: new roles for peripheral dopamine on metabolic control and tumor growth: let's seek the balance. Endocrinology. 2010;151:5570-5581.

94. Maas J, Landis D. Brain norepinephrine and behavior: a behavioral and kinetic study. Psychosom Med. 1965;27:399-407.

95. Przybyla A, Wang S. Neurophysiological characteristics of cardiovascular neurons in the medulla oblongata of the cat. J Neurophysiol. 1967;30:645.

96. Purves M. Do vasomotor nerves significantly regulate cerebral blood flow? Circ Res. 1978;43:485-493.

97. Morillo E, Gardner L. Bereavement as an antecedent factor in thyrotoxicosis of childhood: four case studies with survey of possible metabolic pathways. Psychosom Med. 1979;41:545-555.

98. Brewster D, Dettmar P, Lynn A. Modification of the proline residue of TRH enhances biological activity and inhibits degradation. Eur $J$ Pharmacol. 1980;66:65-71.

99. Brewster D, Dettmar P, Metcalf G. Biologically stable analogues of TRH with increased neuropharmacological potency. Neuropharmacology. 1981;20:497-503.

100. Kawano Y, Ferrario C. Neurohormonal characteristics of cardiovascular response due to intraventricular hypertonic NaCl. Am J Physiol. 1984;247(3 Pt 2):H422-H428.

101. Saito T, Ishizawa H, Tsuchiya F, Ozawa H, Takahata N. Neurochemical findings in the cerebrospinal fluid of schizophrenic patients with tardive dyskinesia and neuroleptic-induced parkinsonism. Jpn J Psychiatry Neurol. 1986;40:189-194.

102. Johnston J, Balachandran A. Effects of dietary protein, energy and tyrosine on central and peripheral norepinephrine turnover in mice. J Nutr. 1987;117:2046-2053.

103. Thomas G, Scott C, Cummins J. Adrenergic regulation of growth hormone secretion in the ewe. Domest Anim Endocrinol. 1994;11: 187-195.

104. Elrod R, Peskind E, DiGiacomo L, Brodkin KI, Veith RC, Raskind MA. Effects of Alzheimer's disease severity on cerebrospinal fluid norepinephrine concentration. Am J Psychiatry. 1997; 154:25-30.

105. Cameron O, Zubieta J, Grunhaus L. Effects of yohimbine on cerebral blood flow, symptoms, and physiological functions in humans. Psychosom Med. 2000;62:549-559.

106. De Keyser J, Zeinstra E, Frohman E. Are astrocytes central players in the pathophysiology of multiple sclerosis? Arch Neurol. 2003;60: 132-136.

107. Rodrigues S, LeDoux J, Sapolsky R. The influence of stress hormones on fear circuitry. Annu Rev Neurosci. 2009;32:289-313.

108. Sobocinska J, Kozłowski S. Osmotic thirst suppression in dogs exposed to low ambient temperature. Physiol Behav. 1987;40:171-175.

109. Weil-Malherbe H, Axelrod J, Tomchick R. Blood-brain barrier for adrenaline. Science. 1959;129:1226-1227.
110. Pinson R, Bloom B, Buck C. Some central nervous system drugs designed from metabolic considerations. Ann NY Acad Sci. 1962;96: 336-344.

111. Baust W, Niemczyk H. Studies on the adrenaline-sensitive component of the mesencephalic reticular formation. J Neurophysiol. 1963;26: 692-704.

112. Berkowitz B, Spector S. Effect of caffeine and theophylline on peripheral catecholamines. Eur J Pharmacol. 1971;13:193-196.

113. Frohman L. Clinical neuropharmacology of hypothalamic releasing factors. N Engl J Med. 1972;286:1391-1397.

114. Mathew R, Ho B, Francis D, Taylor DL, Weinman ML. Catecholamines and anxiety. Acta Psychiatr Scand. 1982;65:142-147.

115. Deniard M, Meignen J, DeFeudis F. Reversal of reserpine-induced ptosis in the mouse by alpha-adrenoceptor-agonists. Psychopharmacology (Berl). 1983;80:243-248.

116. Sarmento A, Borges N, Azevedo I. Adrenergic influences on the control of blood-brain barrier permeability. Arch Pharmacol. 1991;343: 633-637.

117. Taylor J, Neal R, Ford J, Ford TW, Clarke RW. Prolonged inhibition of a spinal reflex after intense stimulation of distal peripheral nerves in the decerebrated rabbit. J Physiol. 1991;437:71-83.

118. Heilman K. The neurobiology of emotional experience. JNeuropsychiatry Clin Neurosci. 1997;9:439-448.

119. Horinaka N, Artz N, Cook M, et al. Effects of elevated plasma epinephrine on glucose utilization and blood flow in conscious rat brain. Am J Physiol. 1997;272:H1666-H1667.

120. Janssen S, Arntz A, Bouts S. Anxiety and pain: epinephrine-induced hyperalgesia and attentional influences. Pain. 1998;76:309-316.

121. Home P. The Effects of Glucose on the Memory and Attention of Newborn Human Infants. Montreal, Canada: School of Dietetics and Human Nutrition McGill University; 1999.

122. Cameron O. Interoception: the inside story - a model for psychosomatic processes. Psychosom Med. 2001;63:697-710.

123. Cameron N, Erskine M. c-FOS expression in the forebrain after mating in the female rat is altered by adrenalectomy. Neuroendocrinology. 2002;77:305-313.

124. De Kloet E, De Jong I, Oitzl M. Neuropharmacology of glucocorticoids: focus on emotion, cognition and cocaine. Eur J Pharmacol. 2008;13:585:473-482.

125. Karlamangla A, Singer B, Greendale G, Seeman TE. Increase in epinephrine excretion is associated with cognitive decline in elderly men: MacArthur studies of successful aging. Psychoneuroendocrinology. 2005;30:453-460.

126. Korte S, Koolhaas J, Wingfield J, McEwen BS. The Darwinian concept of stress: benefits of allostasis and costs of allostatic load and the trade-offs in health and disease. Neurosci Biobehav Rev. 2005; 29:3-38.

127. Sonner J, Xing Y, Zhang Y. Administration of epinephrine does not increase learning of fear to tone in rats anesthetized with isoflurane or desflurane. Anesth Analg. 2005;100:1333-1337.

128. Brandt K, Sünram-Lea S, Qualtrough K. The effect of glucose administration on the emotional enhancement effect in recognition memory. Biol Psychol. 2006;73:199-208.

129. Flint R, Bunsey M, Riccio D. Epinephrine-induced enhancement of memory retrieval for inhibitory avoidance conditioning in preweanling Sprague-Dawley rats. Dev Psychobiol. 2007;49:303-311.

130. Janitzky K, Linke R, Yilmazer-Hanke D. Disrupted visceral feedback reduces locomotor activity and influences background contextual fear conditioning in C57BL/6 JOlaHsd mice. Behav Brain Res. 2007;182: 109-118.

131. Winter B, Breitenstein C, Mooren F, et al. High impact running improves learning. Neurobiol Learning Mem. 2007;87:597-609.

132. Koepsell H, Schmitt BM, Gorboulev V. Organic cation transporters. Rev Physiol Biochem Pharmacol. 2003;150:36-90.

133. Koepsell H. Organic cation transporters in the intestine, kidney, liver, and brain Annu Rev Physiol. 1998;60:243-266. 
134. Ohtsuki S. New aspects of the blood-brain barrier transporters: its physiologic roles in the central nervous system. Biol Pharm Bull. 2004;27:1489-1496.

135. Wa T, Burns N, Williams B, Freestone S, Lee M. Blood and urine 5-hydroxytryptophan and 5-hydroxytryptamine levels after administration of two 5-hydroxytryptamine precursors in normal man. Br J Clin Pharmacol. 1995;39:327-329.

136. Sole M, Madapallimattam A, Baines A. An active pathway for serotonin synthesis by renal proximal tubules. Kidney Int. 1986;29: 689-694.

137. Seri I, Tulassay T, Kiszel J, et al. Effect of low-dose dopamine infusion on prolactin and thyrotropin secretion in preterm infants with hyaline membrane disease. Biol Neonate. 1985;47:317-322.

138. Vieira-Coelho M, Soares-Da-Silva P. Apical and basal uptake of L-dopa and 5-HTP and their corresponding amines dopamine and 5-HT in OK cells. Am J Physiol. 1997;272(5 Pt 2):F632-F639.

139. Wang Z, Srragy H, Felder R, Carey R. Intrarenal dopamine production and distribution in the rat: physiological control of sodium excretion. Hypertension. 1997;29:228-234.

140. Suzuki H, Nakane H, Kawamura M, Yoshizawa M, Takeshita E, Saruta T. Excretion and metabolism of dopa and dopamine by isolated perfused rat kidney. Am J Physiol. 1984;247(3 Pt 1):E285-E290.

141. Adam W, Adams BA. Production and excretion of dopamine by the isolated perfused rat kidney. Renal Physiol. 1985;8:150-158.

142. Kambara S, Yoneda S, Yoshimura M, et al. The source and significance of increased urinary dopamine excretion during sodium loading in rats. Nippon Naibunpi Gakkai Zasshi. 1987;63:657-663. Japanese.
143. Zimlichman R, Levinson P, Kelly G, Stull R, Keiser H, Goldstein D. Derivation of urinary dopamine from plasma dopa. Clin Sci (Lond). 1988;75:515-520.

144. Carey R. Theodore Cooper Lecture: renal dopamine system: paracrine regulator of sodium homeostasis and blood pressure. Hypertension. 2001;38:297-302.

145. Hagege J, Richet G. Proximal tubule dopamine histofluorescence in renal slices incubated with L-dopa. Kidney Int. 1985;27:3-8.

146. Isaac J, Berndt TJ, Knox FG. Role of dopamine in the exaggerated phosphaturic response to parathyroid hormone in the remnant kidney. J Lab Clin Med. 1995;126:470-473.

147. Henry DP, Dentino M, Gibbs PS, Weinberger MH. Vascular compartmentalization of plasma norepinephrine in normal man: the relationships between venous and arterial norepinephrine concentration and the urinary excretion of norepinephrine. J Lab Clin Med. 1979;94:429-437.

148. Buu NT, Duhaime J, Kuchel O. Handling of dopamine and dopamine sulfate by isolated perfused rat kidney. Am J Physiol. 1986;250(6 Pt 2): F975-F979.

149. Boren DR, Henry DP, Selkurt EE, Weinberger MH. Renal modulation of urinary catecholamine excretion during volume expansion in the dog. Hypertension. 1980;2:383-389.

150. Ziegler MG, Aung M, Kennedy B. Sources of human urinary epinephrine. Kidney Int. 1997;51:324-327.

151. Ziegler MG, Kennedy B, Elayan H. Rat renal epinephrine synthesis. J Clin Invest. 1989;84:1130-1133.

152. Cook IA. Biomarkers in psychiatry: potentials, pitfalls, and pragmatics. Prim Psychiatry. 2008;15:54-59.

\section{Publish your work in this journal}

The International Journal of Nephrology and Renovascular Disease is an international, peer-reviewed open-access journal focusing on the pathophysiology of the kidney and vascular supply. Epidemiology, screening, diagnosis, and treatment interventions are covered as well as basic science, biochemical and immunological studies. The journal welcomes original research, clinical studies, reviews \& evaluations, expert opinion and commentary, case reports and extended reports. The manuscript management system is completely online and includes a very quick and fair peer-review system, which is all easy to use. Visit http://www.dovepress.com/testimonials.php to read real quotes from published authors.

Submit your manuscript here: http://www.dovepress.com/international-journal-of-nephrology-and-renovascular-disease-journal 